\title{
A Comparison of Visual vs. Instrumental Measurement of Color Differences in Bentgrass Turf
}

\author{
Peter J. Landschoot ${ }^{1}$ and Charles F. Mancino \\ Department of Agronomy, The Pennsylvania State University, University \\ Park, PA 16802
}

Additional index words. colorimeter, chromameter, turfgrass color, creeping bentgrass, colonial bentgrass, Agrostis capillaris, Agrostis stolonifera, hue angle

\begin{abstract}
This study was conducted to determine: 1) if the Minolta CR-310 Chroma Meter can detect color differences among bentgrass (Agrostis stolonifera L., A. capillaris L.) cultivars maintained as a turf; 2) how the CR-310 parameters of hue angle, lightness, and chroma compare with visual color assessments; and 3 ) if the $C R-310$ can provide consistent color measurements among evaluators. Differences were detected among cultivars with respect to hue angle, lightness, and chroma. Hue angle and chroma were significantly correlated with visual color assessments when data were averaged across all evaluators. Lightness was not strongly associated with visual color assessment. Differences were found among evaluators for visual color assessment, lightness, and chroma, but not for hue angle measurements. Thus, hue angle appears to be the most consistent CR-310 parameter for measuring color of bentgrass turf. These results indicate that the CR-310 can be used to evaluate the color of bentgrass cultivars maintained as a turf and provides consistent hue angle measurements among evaluators, regardless of experience in rating turf color. The CR-310 is probably best used for measuring relative color differences and may be useful if cultivars of similar color are desired in blended turfs.
\end{abstract}

Color is an important component of turf quality and one of the best visual indicators of turf health (Beard, 1973). Although turfgrass color is a personal preference, Beard (1973) stated that most individuals prefer a dark green turf. This statement is supported by greater efforts by turfgrass breeders to develop dark green rather than lighter, yellow-green cultivars. Color is also an important consideration in blending cultivars and mixing turfgrass species. Turfgrass managers generally prefer to blend cultivars and mix species of similar color so that the color is uniform throughout the stand.

Because turf color is important to breeders and practitioners, it is routinely evaluated in cultivar trials. Visual assessments using numerical scales are the most common means of evaluating color. Although visual assessments are fast and easy to perform, they are subject to perception differences among evaluators and may even differ for an individual evaluator on different dates (Birth and McVey, 1968; Gooding and Gamble, 1990). Color charts, such as those developed by the Munsell Color Co. (Baltimore), serve as references that can help evaluators standardize color ratings (American Society for Testing and Materials, 1989; Mills et al., 1995). However, compari-

Received for publication 24 June 1999. Accepted for publication 21 Oct. 1999. The cost of publishing this paper was defrayed in part by the payment of page charges. Under postal regulations, this paper therefore must be hereby marked advertisement solely to indicate this fact.

${ }^{1}$ To whom reprint requests should be addressed; e-mail: pj11@psu.edu sons of chart colors to turf color may vary among evaluators because of perception differences, abnormal color vision, and variable lighting conditions (American Society for Testing and Materials, 1989; Mills and Engelke, 1997).

Portable tristimulus colorimeters have been used to detect color differences among turfgrasses. Kavanagh et al. (1985) measured such differences using the Hunter Color Difference Meter (HunterLab, Reston, Va.). Kimura et al. (1989) found that the Minolta CR-110 Chroma Meter(Minolta Co., Ramsey, N.J.) detected color differences among Agrostis sp., Poa pratensis L., Festuca sp., and Lolium perenne L. cultivars. When used properly, colorimeters provide objective measurements of turf color and allow consistent color evaluations of turf over time (Thorogood et al., 1993).

The Minolta CR-310 Chroma Meter (CR310) may represent an improvement over other colorimeters for assessing turfgrass color since its wide-area, illumination-viewing geometry allows more accurate measurements of textured surfaces (D. Bowden, personal communication). Thorogood et al. (1993) reported that the CR-310 detected color changes in senescing leaf clippings from five $L$. perenne genotypes. Landschoot and Mancino (1997) found that visual color ratings of creeping bentgrass (Agrostis stolonifera L.) fertilized with different rates of $\mathrm{N}$ were strongly correlated with hue angle as measured with a CR310. Although these studies suggest advantages in using the CR-310 for measuring turf color, no published data are available concerning the effectiveness of this device in measur- ing color differences among turfgrass cultivars established in field plots.

The objectives of this study were to determine: 1) if the CR-310 can detect differences in hue angle, lightness, and chroma among creeping and colonial (A. capillaris L.) bentgrass cultivars established in field plots; 2) how CR-310 data compare with visual color assessments; and 3) if the CR-310 can provide consistent hue angle, lightness, and chroma readings among different evaluators for the bentgrass cultivars.

\section{Materials and Methods}

This experiment was conducted during 1997 at the Joseph Valentine Turfgrass Research Center located in University Park, Pa. Eight cultivars of creeping bentgrass and two of colonial bentgrass were established in 1994 and maintained under typical golf course fairway management conditions during 1995, 1996, and 1997. Creeping bentgrass cultivars included '18th Green', 'Cato', 'Southshore', 'Providence', 'Penneagle', 'Penncross', 'Seaside II', and 'Seaside'. Colonial bentgrass cultivars were 'Tendez' and 'SR-7100'. The turf was mowed three times per week during the growing season at a height of $11 \mathrm{~mm}$ and plots were irrigated frequently to prevent drought stress. The preemergence herbicide bensulide [ $S$ - $(O, O$-diisopropyl phosphorodithioate) ester of $\mathrm{N}$-(2-mercaptoethyl) benzenesulfonamide] was applied in May of 1995 and 1996 to control smooth crabgrass (Digitaria ischaemum Schreb. ex Muhl.). Two fungicides, chlorothalonil (tetrachloroisophthalonitrile) and vinclozolin [3-(3,5-dichlorophenyl)-5-ethenyl-5-methyl-2,4oxazolidinedione], were applied regularly during 1995 and 1996 to prevent disease. The turf area was fertilized with methylene urea $(\mathrm{N}$ applied at $146 \mathrm{~kg} \cdot \mathrm{ha}^{-1}$ ) split into four equal applications during 1995 and 1996. In Spring 1997, two methylene urea applications (N applied at $24 \mathrm{~kg} \cdot \mathrm{ha}^{-1}$ ) were made to the test area. The soil type was a Hagerstown silt loam (fine, mixed, mesic, Typic Hapludalf) with a $\mathrm{pH}$ of 7.1, P soil level of $115 \mathrm{~kg} \cdot \mathrm{ha}^{-1}$, exchangeable $\mathrm{K}$ at $1.6 \mathrm{cmol} \cdot \mathrm{kg}^{-1}$, and a cation exchange capacity of $8.4 \mathrm{cmol}_{\mathrm{c}} \cdot \mathrm{kg}^{-1}$.

Cultivar treatments were arranged in a randomized complete-block design with three replications. Plots $(1.2 \times 1.8 \mathrm{~m})$ had complete turf cover (no soil visible through the turf canopy) and no signs of drought stress. Beginning 2 weeks prior to color evaluations, plots were mowed in one direction with a triplex reel mower, with clippings collected in baskets. This procedure ensured that leaf blades were oriented in one direction over the entire sampling area. Plots were not mowed the day before or the day of the color evaluations.

Visual assessments of turf color were made by five individuals (hereafter referred to as evaluators) on 5 June 1997 using a scale of 1 to 9 , with 9 equal to darkest green and 1 equal to a light, yellow-green. All assessments were made in late morning under complete cloud cover. Evaluators 3 and 5 each had over 15 years of experience assessing turfgrass color, 
evaluators 1 and 4 each had 2 years of experience, and evaluator 2 was inexperienced.

Immediately following visual assessments, color measurements were made with a CR310 . The CR-310 consists of a data processor and a 50-mm-diameter measuring head that covers the specimen and excludes all external light. The head uses wide-area illumination, $0^{\circ}$ viewing angle, and a relatively large (1963$\mathrm{mm}^{2}$ ) measuring area. The large area improves accuracy on textured surfaces. A pulsed, xenon arc lamp mounted inside a mixing chamber emits diffuse, uniform light over the measuring area. Light reflected from the specimen is collected by an optical-fiber cable for color analysis (Chroma Meter CR-310 Instruction Manual).

The CR-310 allows measurements in five different color spaces. Color space refers to one of several numerical systems of expressing the color of an object, thus allowing an individual to describe or communicate color. We selected the $\mathrm{L} * \mathrm{C}^{*} \mathrm{H}^{\circ}$ color space to measure turf color, where $\mathrm{L}$ indicates lightness, $\mathrm{C}$ is chroma, and $\mathrm{H}^{\circ}$ is hue angle. Lightness is the attribute of color perception by which a nonself-luminous body is judged to reflect more or less light (American Society for Testing and Materials, 1989). Lightness, in the $\mathrm{L}^{*} \mathrm{C}^{*} \mathrm{H}^{\circ}$ color space, is expressed on a scale extending from 0 for black to 100 for white. Chroma is the attribute of color used to indicate the degree of departure from a gray of the same lightness (American Society for Testing and Materials, 1989) and is expressed on a scale of 0 (gray) to 60 in the $\mathrm{L}^{*} \mathrm{C} * \mathrm{H}^{\circ}$ color space. Hue is the attribute of color perception by which a color is judged to be red, orange, yellow, green, blue, purple, or intermediate between adjacent pairs of these colors, considered in a closed $360^{\circ}$ ring or wheel (American Society for Testing and Materials, 1989). A particular color subtends an angle known as the hue angle (Thorogood et al., 1993). Hue angles of the four primary colors in the $\mathrm{L}^{*} \mathrm{C}^{*} \mathrm{H}^{\circ}$ color space are: red, $0^{\circ}$; yellow, $90^{\circ}$; green, $180^{\circ}$; and blue, $270^{\circ}$.

Prior to data collection, the CR-310 was calibrated with a Minolta Calibration Plate model CR-A44 (Minolta Co.). Five measurements were made on each plot by each evaluator with the same instrument. Although evaluators received no special instructions regarding location of measurements within plots, all tried to choose locations that were representative of the plot area. The five measurements were averaged to provide a single lightness, chroma, and hue angle reading for an individual evaluator on each plot. A previous study demonstrated that five measurements were sufficient to detect color differences among $0.9 \times 3.0-\mathrm{m}$ plots of creeping bentgrass fertilized with different rates of N (Landschoot and Mancino, 1997).

All visual color assessments and CR-310 data were subjected to analysis of variance (ANOVA). The experiment was analyzed as a split-plot with cultivars serving as whole plots and evaluators as subplots. Means of visual assessments and CR-310 data were calculated for each evaluator across all cultivars and for each cultivar across all evaluators. Means were also calculated for data collected by every evaluator for each cultivar. Visual color assessments and CR-310 data were analyzed by ANOVA and means were compared using Fisher's protected least significant difference test $(P \leq 0.05)$. Pearson correlation coefficients were calculated using means of visual color assessments and CR-310 data.

\section{Results and Discussion}

A significant replication affect was observed for all CR-310 parameters (hue angle, lightness, and chroma) when data were averaged across all evaluators (Table 1).

Table 1. Analysis of variance for visual color assessments and CR-310 hue angle, lightness, and chroma values of bentgrass cultivars.

\begin{tabular}{lccccc}
\hline \hline & & \multicolumn{4}{c}{ Mean squares } \\
\cline { 3 - 6 } & & \multicolumn{3}{c}{ CR-310 Chroma Meter } \\
\cline { 3 - 6 } Source & df & Visual assessment & Hue angle & Lightness & Chroma \\
\hline Rep (R) & 2 & $0.02^{\text {Ns }}$ & $10.28^{* *}$ & $29.28^{*}$ & $4.60^{*}$ \\
Cultivar (C) & 9 & $14.68^{* * *}$ & $26.15^{* *}$ & $50.81^{* * *}$ & $22.70^{* * *}$ \\
Error A & 18 & 0.75 & 5.86 & 11.46 & 2.52 \\
Evaluator (E) & 4 & $21.21^{* * *}$ & $3.32^{\text {Ns }}$ & $164.43^{* * * *}$ & $35.56^{* * * *}$ \\
C $\times$ E & 36 & $0.84^{* * *}$ & $1.21^{\text {Ns }}$ & $9.75^{\text {Ns }}$ & $1.95^{\text {Ns }}$ \\
Error B & 80 & 0.28 & 1.49 & 7.95 & 1.36 \\
\hline
\end{tabular}

$\overline{\text { Ns, }, * * *, * * *}$ Nonsignificant or significant at $P \leq 0.05,0.01$, or 0.001 .

Table 2. Mean values for visual color assessments and CR-310 readings of hue angle, lightness, and chroma collected by five evaluators for 10 bentgrass cultivars.

\begin{tabular}{|c|c|c|c|c|}
\hline & \multicolumn{4}{|c|}{ Means of assessments by five evaluators } \\
\hline & Visual assessment $^{2}$ & Hue angle ${ }^{y}$ & Lightness $^{x}$ & Chroma $^{\mathrm{w}}$ \\
\hline \multicolumn{5}{|l|}{ Cultivar } \\
\hline 18th Green & $7.6 \mathrm{a}$ & $122.8 \mathrm{a}$ & $29.5 \mathrm{~b}$ & $14.7 \mathrm{e}$ \\
\hline Cato & $7.2 \mathrm{ab}$ & $121.8 \mathrm{bc}$ & $30.3 \mathrm{ab}$ & $16.9 \mathrm{~d}$ \\
\hline Southshore & $6.9 \mathrm{bc}$ & $122.0 \mathrm{a}-\mathrm{c}$ & $31.6 \mathrm{a}$ & $17.7 \mathrm{bc}$ \\
\hline Providence & $6.5 \mathrm{~cd}$ & $122.1 \mathrm{ab}$ & $30.2 \mathrm{ab}$ & $16.8 \mathrm{~d}$ \\
\hline Penneagle & $6.5 \mathrm{~cd}$ & $122.1 \mathrm{ab}$ & $31.3 \mathrm{ab}$ & $17.8 \mathrm{bc}$ \\
\hline Tendez & $6.2 \mathrm{~d}$ & $119.6 \mathrm{~d}$ & $26.1 \mathrm{c}$ & $18.6 \mathrm{ab}$ \\
\hline Penncross & $6.0 \mathrm{de}$ & $121.2 \mathrm{c}$ & $30.7 \mathrm{ab}$ & $17.5 \mathrm{~cd}$ \\
\hline Seaside II & $5.9 \mathrm{de}$ & $122.8 \mathrm{a}$ & $31.4 \mathrm{ab}$ & $18.0 \mathrm{bc}$ \\
\hline SR-7100 & $5.5 \mathrm{e}$ & $119.3 \mathrm{~d}$ & $27.1 \mathrm{c}$ & $19.2 \mathrm{a}$ \\
\hline Seaside & $4.1 \mathrm{f}$ & $119.8 \mathrm{~d}$ & $30.4 \mathrm{ab}$ & $18.3 \mathrm{ab}$ \\
\hline $\mathrm{LSD}_{0.05}$ & 0.7 & 0.9 & 2.1 & 0.9 \\
\hline \multicolumn{5}{|l|}{ Evaluator } \\
\hline 1 & $5.1 \mathrm{~d}$ & 121.6 & $31.6 \mathrm{a}$ & $18.1 \mathrm{a}$ \\
\hline 2 & $7.4 \mathrm{a}$ & 120.9 & $30.8 \mathrm{a}$ & $18.1 \mathrm{a}$ \\
\hline 3 & $6.5 \mathrm{~b}$ & 121.2 & $32.0 \mathrm{a}$ & $18.6 \mathrm{a}$ \\
\hline 4 & $5.8 \mathrm{c}$ & 121.7 & $26.7 \mathrm{~b}$ & $15.9 \mathrm{c}$ \\
\hline 5 & $6.4 \mathrm{~b}$ & 121.5 & $28.1 \mathrm{~b}$ & $17.0 \mathrm{~b}$ \\
\hline $\mathrm{LSD}_{0.05}$ & 0.3 & NS & 2.1 & 0.6 \\
\hline
\end{tabular}

${ }^{2}$ Based on scale of 1 to 9 , with $9=$ darkest green and $1=$ light yellow-green.

${ }^{y} \mathrm{Hue}$ angles of the four primary colors are: red, $0^{\circ}$; yellow, $90^{\circ}$; green, $180^{\circ}$; and blue, $270^{\circ}$.

${ }^{x}$ Expressed on a scale extending from 0 for black to 100 for white.

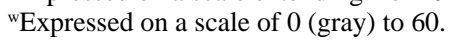

Table 3. Summary of analysis of variance for visual color assessments and CR-310 hue angle, lightness, and chroma values collected by five evaluators for 10 bentgrass cultivars.

\begin{tabular}{|c|c|c|c|c|c|}
\hline & \multicolumn{5}{|c|}{ Evaluator } \\
\hline & 1 & 2 & 3 & 4 & 5 \\
\hline $\begin{array}{l}\text { Visual } \\
\text { assessment }\end{array}$ & *** & **** & $* * *$ & **** & **** \\
\hline Hue angle & $* *$ & $* *$ & * & NS & $*$ \\
\hline Lightness & NS & NS & NS & $* *$ & * \\
\hline Chroma & $* *$ & $* *$ & $* * *$ & $* *$ & NS \\
\hline
\end{tabular}


Table 4. Summary of analysis of variance for visual color assessments and CR-310 hue angle, lightness, and chroma values collected by five evaluators for 10 cultivars of bentgrass.

\begin{tabular}{|c|c|c|c|c|c|c|c|c|c|c|}
\hline & \multicolumn{10}{|c|}{ Cultivar } \\
\hline & 18th Green & Providence & Seaside & Cato & Southshore & SR 7100 & Penncross & Seaside II & Penneagle & $\overline{\text { Tendez }}$ \\
\hline $\begin{array}{l}\text { Visual } \\
\text { assessment }\end{array}$ & $*$ & $*$ & $* * *$ & $* * *$ & $*$ & $* * *$ & $* * *$ & $* *$ & $* * *$ & $* * *$ \\
\hline Hue angle & NS & NS & NS & NS & NS & NS & NS & NS & NS & NS \\
\hline Lightness & NS & NS & NS & $*$ & NS & $*$ & $* *$ & NS & NS & NS \\
\hline Chroma & NS & NS & $*$ & $*$ & NS & NS & $* *$ & NS & NS & $* *$ \\
\hline
\end{tabular}

ss, ${ }^{*}, * *, * * *$ Nonsignificant or significant at $P \leq 0.05,0.01$, or 0.001 , respectively.

Although hue angle and chroma were correlated with visual color assessments, data from certain cultivars did not conform to expected trends (Table 2). For example, 'Seaside II' received the highest hue angle (122.79), but a low visual assessment, score (5.9). In these cases, evaluators may have visually assessed color differently for certain cultivars. Certain cultivar characteristics, such as density, texture, growth habit, and glossiness of leaf blades, also may influence CR-310 parameters differently than they do evaluator perceptions of color. The effects of turf density, texture, leaf glossiness, and growth habit on colorimeter readings have not been investigated.

Differences were found among evaluators with respect to visual color assessments, chroma, and lightness (Tables 1, 2, and 4). Only hue angle data were consistent among all evaluators for the 10 bentgrass cultivars. Cultivar $\times$ evaluator interaction was significant for visual assessments, but not for any of the CR-310 parameters (Table 1). This interaction indicates that evaluators were inconsistent when using the visual assessment method or were not using the 1-9 scale in the same manner. Horst et al. (1984) reported a similar interaction in a study involving visual quality assessments of turfgrass cultivars by multiple evaluators.

Experience of the evaluators in rating color may have had some influence on the cultivar $x$ evaluator interaction. Visual assessments by the two most experienced evaluators ( 3 and 5) did not differ, whereas evaluators with 2 years of experience (1 and 4) differed from one another and from evaluators 3 and 5 (Table 2). The inexperienced evaluator (2) assigned the highest scores. Two reports suggest that visual assessment may not always be affected by experience. Skogley and Sawyer (1992) reported that 12 of 14 researchers experienced in subjective field data collection showed good consistency in rating quality, density, and groundcover, but not color. Landschoot and Mancino (1997) reported differences in color ratings between two experienced evaluators for a $\mathrm{N}$ trial with creeping bentgrass.

Evaluator differences for lightness and chroma are difficult to interpret. One reason for the differences may be that lightness and chroma measurements are more sensitive than hue angle to subtle density, texture, and mowing irregularities within some plots. Because evaluators sample different areas within plots, these irregularities may cause variation in light- ness and chroma measurements among some evaluators for certain cultivars (Table 4). Previous studies of turfgrasses using the CR-310 revealed that hue and hue angle were better indicators of turf color than were lightness and chroma (Landschoot and Mancino, 1997; Thorogood et al., 1993).

In conclusion, this study demonstrates that evaluators can detect color differences among bentgrass cultivars visually. However, results confirm previous reports that visual assessments of turfgrasses are subjective and can vary among evaluators (Horst et al., 1984; Skogley and Sawyer, 1992). Although the CR-310 hue angle was not as sensitive as the visual assessment method in detecting color differences among cultivars, it provided more consistent measurements among evaluators, regardless of experience in rating turf color. Although these results indicate potential in using the CR-310 for measurements of bentgrass cultivars of uniform color maintained as a dense stand, further evaluation under a range of environments and by more evaluators is necessary to fully assess its value for routine color measurements. Information derived from this study should not be applied to other turfgrass species or management situations without further testing.

Portable tristimulus colorimeters are easy to operate and provide relatively rapid color measurements of turfgrasses. About $6 \mathrm{~s}$ are required for the CR-310 to record, process, and print the results of one lightness, chroma, and hue angle measurement. During the $6 \mathrm{~s}$, the evaluator can transport the unit to another location to sample. Other objective methods of turf color determination exist, such as chlorophyll analysis, but are rarely used because they are labor-intensive, time-consuming, and may not take into account characteristics of established, field-grown turf that affect color (Birth and McVey, 1968). Colorimeters are used in textile, paint, and plastic industries as an objective means of standardizing color and detecting color differences among product samples. They can also be used to indicate the color of a product, on a numerical basis. $\mathrm{Nu}-$ merical color descriptions of individual turfgrass cultivars are probably not as important to breeders and practitioners because turfgrass color can be influenced by fertilizers, environmental conditions, growth regulators, and pests. Colorimeters are probably most useful for comparing colors of various bentgrass cultivars maintained under uniform growing conditions. Results could then be used to determine color differences and to develop cultivar blends of uniform color. For example, based on this study, 'Cato' (hue angle 121.81, lightness 30.34, and chroma 16.87) and 'Providence' (hue angle 122.11, lightness 30.18 , chroma 16.80) are closely matched; thus, they may represent a desirable blend of cultivars to ensure uniform color of a turf.

\section{Literature Cited}

American Society for Testing and Materials. 1989. Standard test method for specifying color by the Munsell System. D 1535-89 Annual book of ASTM standards. Amer. Soc. for Testing and Materials, Philadelphia.

Beard, J.B. 1973. Turfgrass science and culture Prentice-Hall, Englewood Cliffs, N.J.

Birth, G.S. and G.R. McVey. 1968. Measuring the color of a growing turf with a reflectance spectrophotometer. Agron. J. 60:640-643.

Gooding, M.J. and L.J. Gamble. 1990. Colour evaluation of Poa pratensis cultivars. J. Sports Turf Res. Inst. 66:134-140.

Horst, G.L., M.C. Engelke, and W. Meyers. 1984. Assessment of visual evaluation techniques. Agron. J. 76:619-622.

Kavanagh, T., D. O'Beirne, and T.P. Cormican. 1985. Use of the Hunter Colour Difference Meter for colour evaluation in turfgrass experiments, p. 255-261. In: F. Lemaire (ed.). Proc. 5th Intl. Turfgrass Res. Conf., Avignon, France. Inst. Natl. Recherche Agron., Paris.

Kimura, T., H. Misawa, and T. Ochiai. 1989. Measuring seasonal changes in leaf color of cool season turfgrass using a chroma meter, p. 411414. In: H. Takatoh (ed.). Proc. 6th Intl. Turfgrass Res. Conf., Tokyo. Jpn. Soc. Turfgrass Sci., Tokyo.

Landschoot, P.J. and C.F. Mancino. 1997. Assessment of the Minolta CR-310 Chroma Meter for predicting nitrogen status of Agrostis stolonifera L. Intl. Turfgrass Soc. Res. J. 8:711-718.

Mills, J.M. and M.C. Engelke. 1997. Calibration of visual and electronic color ratings of turf performance trials, p. 132. In: Agron. Abstr. 1997, Anaheim, Calif.

Mills, J.M., S.K. Riffell, and M.C. Engelke. 1995. Assessing visual color ratings of turf performance trials, p. 150. In: Agron. Abstr. 1995, St. Louis.

Skogley, C.R. and C.D. Sawyer. 1992. Field research, p. 589-610. In: D.V. Waddington, R.N Carrow, and R.C. Shearman (eds.). Turfgrass. Amer. Soc. Agron., Madison, Wis.

Thorogood, D., P.J. Bowling, and R.M. Jones. 1993. Assessment of turf colour change in Lolium perenne L. cultivars and lines. Intl. Turfgrass Soc. Res. J. 7:729-735. 